\title{
The Composition of Capital and the Rate of Profit: A Reply to Laibman
}

Frank Thompson

\begin{abstract}
In response to a critique by Laibman (1996) of earlier work (Thompson 1995) exploring the effect of technical change and accumulation on the real wage rate and thus, via the Okishio Theorem, the rate of proflt, it is demonstrated that in a wide range of one-sector models (including that of Lalbman) of a capitalist economy, increases in the composition of capital do not cause a fall in the equilibrium rate of profit. On the contrary, if anything, increases in the composition of capital cause the rate of profit to be higher.
\end{abstract}

I welcome David Laibman's recent article in this journal (Laibman 1996) as a thoughtful contribution to the continuing investigations of the relations among technical change, accumulation, and the rate of profit. Though there is far more of importance upon which Laibman and I are in agreement than in disagreement, his presentation does however crucially misrepresent my main argument which appeared here earlier (Thompson 1995) and, much more importantly, fails to come to grips with the fact that that argument fundamentally undermines a conception of the "falling tendency of the rate of profit" which has been central to the Marxist tradition.

Rather than indulging in a tedious point-by-point examination of Laibman's comments, I begin instead by refocusing on an implication of my argument which, had I made it explicit at the time, should have made the issues at stake much clearer. Sections I-III are devoted to this task. Having done so I then take up the points of Laibman which are truly at issue.

I am grateful for comments on earlier versions of this work by Douglas Koritz, Patrick Mason, Gary Mongiovi, and participants in the URPE at ASSA session, "New Theory on Technical Change and the Profit Rate," in New Orleans, 4 January 1997, especially David Laibman and Gil Skillman. 


\section{I.}

A main constructive task of this current paper is to demonstrate the following in a standard model of a capitalist economy: a rising composition of capital does not drive a falling rate of profit. If anything, a rising composition of capital drives a rising rate of profit.

The contrary belief that a rising composition of capital drives a falling rate of profit is a fundamental misconception in a large stream of the Marxian tradition, a misconception which confounds understanding that a falling rate of profit is driven by rising costs of which the most salient is the cost of labor power. Over thirtyfive years ago Okishio showed, in an unignorable standard model, that, if technical change is viable in the sense that it would increase the profit rate at current relative prices, the profit rate falls only if the real wage rate rises, a result which has been broadly generalized since then. But, in fact, a rising composition of capital, if anything, ceteris paribus lowers the real wage rate. Thus, a rising composition of capital, if anything, raises the rate of profit.

The story according to which a rising organic composition of capital drives a tendency for the rate of profit to fall is venerable. 1 Why this story could have been so widely accepted should be regarded as an important uninvestigated question in the history of ideas. For, even prior to a formal refutation, it should be obvious that something is amiss. For the organic composition of capital is, in any conception, increasing in the capital/labor ratio and decreasing in the real wage rate. But a rise in the capital/labor ratio ceteris paribus decreases the demand for labor and thus, if anything, puts downward pressure on the real wage rate. And a fall in the real wage rate ceteris paribus increases the rate of profit. That is, when one looks either at the capital/labor ratio or directly at the real wage rate, one sees that what raises the organic composition of capital lowers, if anything, the real wage rate and thus raises, not lowers, the rate of profit. This view is directly contrary to any notion of a rising organic composition of capital driving a falling rate of profit.

Of course this is an informal argument. It employs ceteris paribus clauses and ignores, for example, that the organic composition of capital can rise even when the capital/labor ratio falls or, alternatively, when the real wage rate rises. The argument needs to be made rigorously precise.

1 The locus classicus is of course Part III of Volume III of Capital, constructed by Engels from Marx's notes. According to Engels in his introduction, this was among the sections in which he was "able to keep almost completely to the original manuscript, apart from stylistic editing" (Marx 1981: 94). 
To do so we assume a one-period, one-sector, fixedproportions-technology model, i.e., a standard one-sector "circulating-capital" model, in which $K$ is the aggregate capital input and $k$ is the capital input/output coefficient (in materialunits/material-units), and in which $L$ is aggregate labor input and $l$ is the labor input/output coefficient (in labor-units/ material-units). Output is $\min [K / k, L / l]$ and thus profit maximizing firms will insure that $K / k=L / l .2,3$ That is, labor demand is

$$
L=l K / k \text {. }
$$

For the next period firms choose a feasible technology, $k^{\prime}, l^{\prime}$, and level of investment, $K^{\prime}$. which determines a level of labor demand, $L^{\prime}=l^{\prime} K^{\prime} / k^{\prime}$.

The Okishio viability assumption is the premise that a feasible technology is chosen only if, evaluated at initial relative prices including the initial real wage rate, $w$, the profit rate would be higher. Okishio's celebrated theorem then establishes, for a large class of fixed-proportions-technology models, that, given a constant real wage rate, the equilibrium rate of profit rises with the introduction of viable technical change.

Of course there is no reason to expect the wage rate to remain the same after a change in technology and, perhaps, change in the level of investment. Okishio's theorem in no way precludes that, in the course of viable technical change, the rate of

2 In this model $K$ and $L$, capital and labor utilized, are endogenous while $k$ and $l$, the capital and labor input/output coefficients, 1.e., the technology, are exogenous. $K$ is constrained not to exceed the (exogenous) capital available, and profit-maximizing capitalists will utilize all the capital avallable if the rate of proflt is positive. Here $Y=K / k=L / 1$ is no "tautology" but rather the outcome of profit maximization. Cf. Thompson 1995: 122 (ft. 1).

3 The setup of this particular model assumes that "labor is paid at the end of the period," 1.e., that firms' capital outlays are only for materials. Nothing of significance turns on this modeling choice.

A more general approach is as follows: Use $M$ instead of $K$ for the aggregate material input and $m$ instead of $k$ for the materials input/output coefficient. In general, the rate of profit is $r=\frac{1-m-w 1}{m+\alpha w 1}$ and the aggregate capital input is $K=M+w L$ where $0 \leq \alpha \leq 1$. For example, if "labor is paid at the beginning of the period," $\alpha=1$ and $K+M+w L$. But if $\alpha=0$ "labor is paid at the end of the period, $K=M$, and it is appropriate to use $k$ instead of $m$ for the materials input/output coefficient. Nothing significant in the argument here depends on the choice of a value for $\alpha$. 
profit will in fact fall. Its import is rather to focus attention on how technical change and accumulation affect the wage rate. For, the rate of profit will fall in the course of viable technical change only if the real wage rate rises.

The obvious step beyond Okishio is thus to endogenize changes in the real wage rate, in particular to specify how changes in the real wage rate are affected by technical change and capital accumulation.

\section{III.}

Our subsequent analysis is facilitated if we examine the results of this choice of technology and investment level using greek letters to represent proportional changes in these variables, i.e., $\mathrm{K}=\left(K^{\prime}-K\right) / K, \quad \kappa=\left(k^{\prime}-k\right) / k, \quad \Lambda=\left(L^{\prime}-L\right) / L, \quad \lambda=\left(l^{\prime}-l\right) / l$, and, where $w^{\prime}$ is the real wage rate which obtains in the next period, $\omega=\left(w^{\prime}-w\right) / w$. Assuming that none of the italic letter variables can take negative values, i.e., there can be neither negative capital nor labor and the real wage rate is non-negative, implies that none of these greek letter variables take values less than minus one, i.e., $\mathrm{K}, \kappa, \Lambda, \lambda, \omega \geq-1$.

As a minimal endogenization of changes in the real wage rate, I have proposed a "Minimal Assumption" that the real wage rate is non-decreasing in labor demand (Thompson 1995: 107). One way to specify this assumption is in terms of the labor demand elasticity of the wage rate, i.e., that this elasticity is non-negative. That is, where $\varepsilon$ is the labor demand elasticity of the real wage rate, the Minimal Assumption is

$$
\frac{\omega}{\Lambda}=\varepsilon \geq 0
$$

Minimal as this assumption is in endogenizing the determination of changes in the real wage rate by technical change and accumulation, it has noteworthy consequences. One consequence I focused on is that, in the absence of accumulation, i.e., when $\mathrm{K} \leq 0$, viable capital-using technical change, i.e., technical change in which $\kappa \geq 0$, does not decrease but rather increases the rate of profit. More generally, "in the absence of sufficient positive accumulation" 4 to offset its effects on labor demand, viable capital using technical change increases the rate of profit. This more general formulation was deplorably inexact, and a main aim here is to make it precise.

4 Thompson 1995: 121, a phrase on which Lalbman focused. See Section IV below. 
It is easy enough to do so. If we rewrite the Minimal Assumption in terms of proportional changes in $K, k$, and $l$, as

$$
\omega=\varepsilon\left[\frac{(1+K)(1+\lambda)}{1+\kappa}-1\right]
$$

it is obvious by inspection and explicit in the partial derivative

$$
\frac{\partial \omega}{\partial \kappa}=-\varepsilon\left[\frac{(1+K)(1+\lambda)}{(1+\kappa)^{2}}\right] \leq 0
$$

$\omega$ non-increasing in $\kappa$

that for a given rate of accumulation $\mathrm{K}$ and proportional change in the labor input/output coefficient $\lambda$, a marginal increase in the proportional growth of the capital input/output ratio $\kappa$ decreases, if anything, the proportional change in the real wage rate. 5 The "if anything" qualifier is needed to include the case in which the Minimal Assumption is only just satisfied, i.e., the case in which $\varepsilon=0$ and thus the wage rate is entirely unaffected by changes in labor demand. But if $\varepsilon>0$, then $\partial \omega / \partial \kappa$ is strictly negative and a (labor demand decreasing) increase in the capital intensity of the technology renders the wage rate lower and (given the Okishio Theorem) the profit rate higher than they would otherwise be.

This is not to say that there cannot be combinations of accumulation and viable technical change, including capital-using technical change, in which the wage rate rises and the profit rate falls. There certainly can be, though only if accumulation is positive. 6 But in such cases the capital-using character of the technical change "works against" any rise in the wage rate, and thus fall in the rate of profit. At every point, increasing $\kappa$ lowers $\omega$, and decreasing $\kappa$ raises $\omega$.

My focus on capital-using technical change in the earlier article stemmed from my attention to the thought-provoking work

5 The partial derivative is appropriate if viability is more than barely satisfied. If not it can be taken into account that $d \lambda / d \kappa<0$ with the same result that $\omega$ is non-increasing in $k$.

6 That positive accumulation is a necessary condition for viable capital-using technical change, increasing the wage rate and thus lowering the rate of profit, was shown in Thompson 1995 . The point can be quickly reiterated:

The viability condition is $\lambda<-q \kappa$, where $q$ is a positive constant determined by the initial conditions. Thus

$$
\omega>\varepsilon\left[\frac{(1+K)(1-q \kappa)}{(1+\kappa)}-1\right]
$$

and thus $\omega>0$ only if $K>0$. 
of Duncan Foley on this topic. ${ }^{7}$ Here I wish to refocus the point in terms more resonate in a broader Marxian tradition, the terms of the "composition of capital."

\section{IV.}

Proper understanding of the notions of "organic," "value," and "technical composition" is Marxologically disputed. The one-sector circulating capital model is too austere to carry one far in such discussions. Here the "organic" or, perhaps better, the "value" composition of capital is taken as the ratio of the value of the material input, "constant capital," to the value of real wages, "variable capital," or, since value in the numerator and denominator cancel out in a one-sector model, simply $K / w L$, or, per unit of output, $t$. And here the only candidate for the technical composition of capital, say $t$, is simply the capital/labor ratio, $K / L=k / l$.

The proportional change in the organic or value composition of capital, say $\gamma$ is then

$$
\gamma=\frac{1+\kappa}{(1+\omega)(1+\lambda)}-1
$$

or, using $\tau=\left(t^{\prime}-t\right) / t$ for the proportional change in the technical composition of capital,

$$
\gamma=\frac{1+\tau}{1+\omega}-1
$$

We can now rewrite the Minimal Assumption as

$$
\omega=\varepsilon\left[\frac{1+\mathrm{K}}{1+\tau}-1\right] .
$$

Then we note, from the specification of the composition of capital, that

$$
(1+\tau)=(\gamma+1)(\omega+1) .
$$

Substituting the latter into the former we have

$$
\omega=\varepsilon\left[\frac{1+K}{(1+\gamma)(1+\omega)}-1\right]
$$

7 Foley 1986: 136-139. 
or equivalently

$$
(\varepsilon+\omega)(1+\omega)(1+\gamma)-\varepsilon(1+K)=0 .
$$

A differential of this last, assuming $\mathrm{dK}=0$, gives us our main result: 8

$$
\frac{\mathrm{d} \omega}{\mathrm{d} \gamma}=-\frac{(\varepsilon+\omega)(1+\omega)}{(\varepsilon+\omega+1+\omega)(1+\gamma)} \leq 0 \quad \omega \text { non-increasing in } \gamma
$$

That is, at a given rate of accumulation, a marginal increase in the proportional growth of the composition of capital does not raise but rather, if anything, decreases the proportional change in the real wage rate. In particular, increasing the composition of capital if anything renders the real wage rate lower than it would otherwise be and thus, given the Okishio Theorem, does not lower but rather, if anything, raises the equilibrium rate of profit.

Stating the same point with use of some traditional phraseology, a rising composition of capital is, if anything, a countervailing tendency to any tendency of the rate of profit to fall. For a rise in the composition of capital ceteris paribus lowers the demand for labor, which, if anything, lowers the real wage rate and raises the rate of profit.

More specifically, if the wage rate is unaffected by changes in labor demand, i.e., if $\varepsilon=0$, then $\mathrm{d} \omega / \mathrm{d} \gamma=0$, and changes in the composition of capital have no effect whatsoever on the wage rate. In particular such changes do not raise the wage rate, which by the Okishio Theorem is a necessary condition for the rate of profit to fall.

On the other hand, if the labor demand elasticity of the wage rate is positive, i.e., if $\varepsilon>0$, then the inequality $\mathrm{d} \omega / \mathrm{d} \gamma<0$ is strictly satisfied. In this case the position of the relation between change in the composition of capital and change in the real wage rate depends on accumulation. But whether accumulation is negative (disaccumulation), zero, or positive, the relation between change in the composition of capital and change in the real wage rate is in every case inverse. That is, as the following figure illustrates, at any rate of accumulation, a rise in the composition of capital lowers the real wage rate. 9

\footnotetext{
8 Note that the non-negativity assumptions imply that $\varepsilon+\omega \geq 0$.

9 The graph depicts $(\varepsilon+\omega)(1+\omega)(1+\gamma)-\varepsilon(1+K)=0$ with $\varepsilon=1$ and $\mathrm{K}=-0.5,0.0,+0.5$.
} 


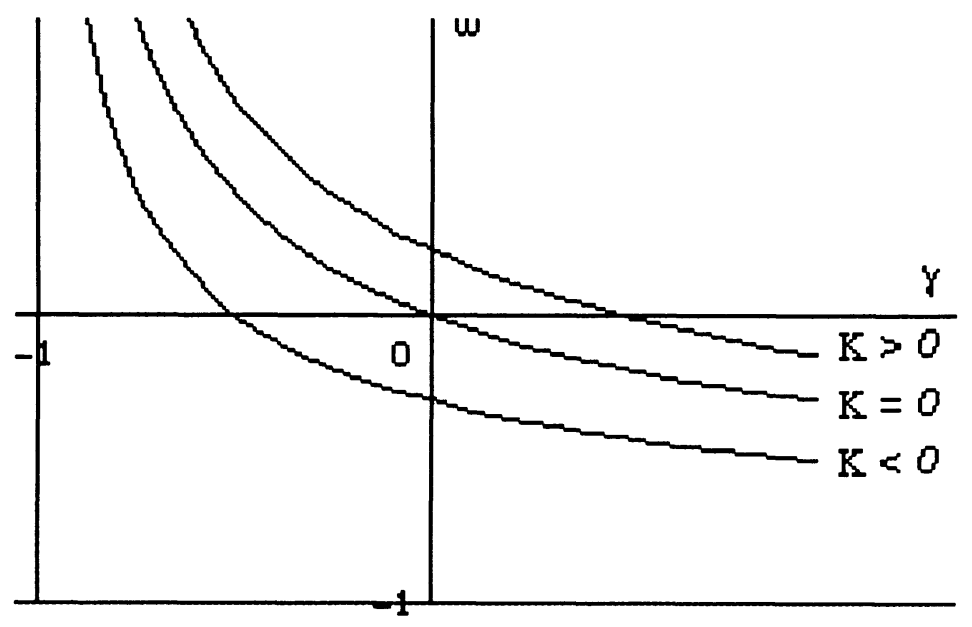

The figure also makes visibly clear a point which may be confused. If and only if accumulation is positive, i.e., $\mathrm{K}>0$, is it possible for both the change in the wage rate and the change in the composition of capital to be positive, i.e., there are values in the positive quadrant. That is, there are combinations of technical change and accumulation in which both the composition of capital and the real wage rate increase. Under such circumstances, in particular given the rise in the wage rate, the rate of profit can fall. But this possibility of a fall in the rate of profit is due entirely to the positive accumulation. The relation between change in the composition of capital and change in the wage rate is nonetheless (as always for $\varepsilon>0$ ) negative; curves are downwardly sloped. This is the sense in which even in cases in which the real wage rate rises and the profit rate falls, a rising composition of capital remains a countervailing tendency. That is, the more the composition of capital rises, the less the profit rate falls.

Thus a claim that a rising composition of capital can cause (promote, drive, lead to, etc.) a falling rate of profit is not at all established by the fact that, simultaneously, the composition of capital can rise while the rate of profit falls. On the contrary, such a fall in the rate of profit must be due to other causes (e.g., accumulation, driving up the wage rate), for which the rising composition of capital is a countervailing force in the straightforward sense that the fall in the rate of profit would have been larger had the rise in the composition of capital been smaller.

\section{V.}

I turn now to Laibman's paper which is intended, as he states in his abstract, to show "the ubiquitous possibility of viable technical changes that raise the composition of capital and lower the rate of profit." (Laibman 1996: 33.) That technical 
change and accumulation can jointly raise the composition of capital and lower the profit rate was a point quite explicitly made in my article as well. But of course the prospect of viable technical change that raises the composition of capital and raises the profit rate is, to say the least, no less prominent. That is to say, the possibility Laibman wishes to focus on is certainly not ubiquitous.

Contrary to the impression Laibman often labors to present, the analyses in our two papers have much in common. These similarities are obscured in part by differences in the models we choose to work with. While I use a circulating capital model, i.e., a model in which the per period depreciation rate of capital is 100 percent, Laibman employs a model with fixed capital with a per period depreciation rate of zero. Doubtless any formalization of Marxian notions has a Procrustean quality. But some are more so than others. Laibman, for example, chooses to call the capitalstock/output-flow ratio, i.e. $k$ here 10 , the "composition of capital," a formulation which strikingly renders the composition of capital entirely independent of labor.

But our common ground is obscured at least as much by summary descriptions Laibman offers at several points which misrepresent the method and conclusions of my paper. Thus, contra Laibman, I do not argue against the existence of "any plausible connection between capital-using technical change and a falling rate of profit" (Laibman 1996: 33). On the contrary I make clear what that connection is, and argue rather that a certain alleged connection, that capital-using technical change induces a falling rate of profit, is spurious. Nor is the whole thrust of my argument, again contra Laibman, one of "casting doubt on the central Marxist claim that individually rational capitalist behavior leads to systematically irrational results..." (Laibman 1996: 35). While I do belabor the fact that viable technical change ("individually rational capitalist behavior") under certain circumstances raises rather that lowers the profit rate, I delineate as well several sets of circumstances in which viable technical change lowers the profit rate ("systematically irrational results"). Moreover I describe hitherto unnoted classes of cases in which higher profit rates are feasible but inaccessible to individually rational capitalists. 11 I never say, imply, or even intimate that "capitalism's internal processes are not contradictory; that micro- and macrorationality basically coincide..." (Laibman 1996: 52, emphasis in original). The fact of the matter is that the results of some individually rational capitalist behavior are good for capitalists and some others are not. The task is to determine which is which.

In the body of his paper Laibman makes use of my Minimal Assumption that the real wage rate is non-decreasing in labor

$10 Q$ for Lalbman. See section VI below.

11 Thompson 1995: 114, 119, and footnotes 27 and 28. 
demand. Nevertheless, he describes this assumption as a "rather extensive capitulation to the neoclassical apparatus of counterfactual demand and supply curves" (Laibman 1996: 41), a description which is thoroughly unwarranted. The assumption is entirely compatible with "rigorous treatment of the labor-power market in Marxist terms" (ibid.) and more generally with treatments which reject (as I emphatically do) the neoclassical assumption that labor markets clear at equilibrium, as I explicitly stated when the Minimal Assumption was introduced (Thompson 1995: 106).

Yet even if Laibman overreaches in attempting to distinguish his analysis from mine at certain points, there is a real disagreement. Informally put, Laibman still wishes to defend the traditional position that in some sense technical change which is capital-using and/or which increases the composition of capital (which are identical in Laibman's model) can or does drive a falling rate of profit. I hold that the traditional position is fundamentally misconceived.

My original argument for this was not as clear as it should have been. In particular I was insufficiently precise in relating the rate of accumulation to the change in technology and composition of capital, an imprecision which Laibman quite legitimately attempts to takes advantage of.

That imprecision is corrected in sections I-III above in which the proposition has been rigorously formulated and proved that, at any given rate of accumulation, increasing the composition of capital (or increasing the capital intensity of the technology) lowers, if anything, the real wage rate and thus increases the rate of profit. Only the special case of this proposition was rigorously demonstrated in the preceding paper: that at a zero rate of accumulation, a rising composition of capital or capital-using technical change lowers, if anything, the real wage rate and thus increases the rate of profit.

Laibman grants this last point at least, but does not recognize how much he has even then conceded. Thus I am, alas, certain that Laibman is profoundly mistaken in thinking that his hypothetical proposal "on behalf of a collective of Marxists interested in the study of capitalism's immanent contradictions"that we "immediately stipulate to the conclusion that in the absence of accumulation [capital-using]12 technical change cannot lead to a falling rate of profit" (Laibman 1996: 43-44)-is uncontroversial and innocuous. For so to stipulate is to grant that capital-using technical change-to the same conclusion, a rising composition of capital-is a countervailing tendency opposed to a

12 The supplement in brackets renders the proposal what Laibman intends: that (viable) capital-saving technical change can lead to a falling rate of profit even in the absence of accumulation is clear. 
falling rate of profit. A collective of Marxists currently willing to grant this conclusion is at best only in formation.

Laibman's air of opposition aside, given his assumptions Laibman must come to the same conclusion that I have, that an increasing composition of capital is, if anything, a force driving the real wage rate lower and the profit rate higher. Perhaps the best way to make this point is to prove the counterpart of the above propositions, $\omega$ non-increasing in $\kappa$ and $\omega$ non-increasing in $\gamma$, in Laibman's own model. It is easy to do so.

Laibman identifies the composition of capital with $Q$, the capital input-output coefficient. $Q=K / X$ where $K$ is the (undepreciating) capital stock and $X$ is (net = gross) output. That is, in Laibman's model capital-using technical change and increasing the composition of capital are collapsed together-made identical by definition. For Laibman output is $\min [K / Q, L / l]$ where $L$ is the labor input and $l$ is the labor input-output coefficient. Thus profit maximizing firms will insure that $K / Q=L / l$ and labor demand is $L=l K / Q$. The real wage rate is $w$.

To distinguish Laibman's model from my own, we can use "hats" on his variables to denote their proportional rates of change. Thus, the Minimal Assumption in Laibman's model is simply

$$
\hat{w}=\varepsilon\left[\frac{(1+\hat{K})(1+\hat{l})}{1+\hat{Q}}-1\right]
$$

where the labor demand elasticity of the real wage rate $\varepsilon \geq 0$.

It follows trivially from the Minimal Assumption in Laibman's model that $\partial \hat{w} / \partial \hat{Q} \leq 0$, that if $\varepsilon=0$ then $\partial \hat{w} / \partial \hat{Q}=0$, and that if $\varepsilon>0$ then $\partial \hat{w} / \partial \hat{Q}<0$. That is, in Laibman's own model, increasing the composition of capital or (for Laibman identically) the capital coefficient, if anything, makes the real wage rate lower and the rate of profit higher than they would otherwise be. 13

Demonstrating this result in Laibman's own model provides an occasion to note again that this result is compatible with some combinations of technical change and accumulation resulting in higher compositions of capital and higher wage rates (and thus lower profit rates), though of course only if accumulation is positive. But in such cases it remains still true that the higher wage rate is due entirely to positive accumulation, not to the higher composition of capital. Rather, the higher the composition

13 The partial derivative is appropriate if viability is more than barely satisfied. If not it can be taken into account that $\mathrm{d} \hat{l} / \mathrm{d} \hat{Q}<0$ with the same result that $\hat{w}$ is non-increasing in $\hat{Q}$. Cf. footnote 5 above. 
of capital, the lower the wage rate as is evident from the following figure.

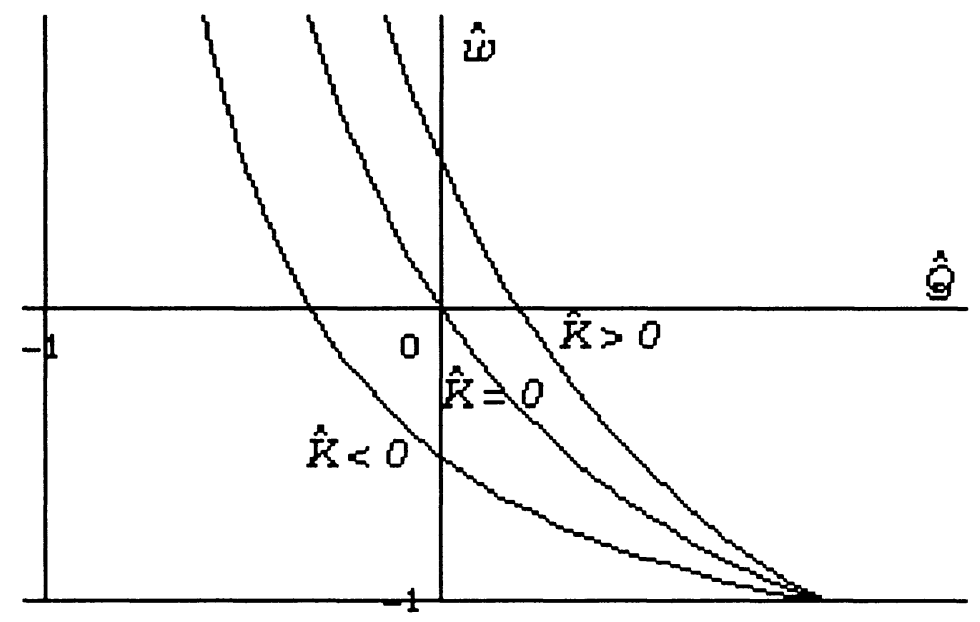

\section{VI.}

I take up here the final section in Laibman's paper ( $\S$ III, pp. $46 \mathrm{ff}$.) in which he delineates his so-called "consistent path" of technical change and accumulation which can feature a rising composition of capital and a falling rate of profit. I of course agree that such a path is possible in the sense of being consistent within the model; the profit rate raising effects of a rising composition of capital can be outweighed by profit rate lowering effects of accumulation (raising the real wage rate which is the Okishio prerequisite for a falling rate of profit). But Laibman provides no reason to expect this interesting possibility to be realized.

Laibman's focus on this possibility is explicitly motivated by a view of technical change which, in the absence of additional argument to support it, is simply unwarranted. "Technical changes do not fall from the sky; there is a tradeoff between reducing one input coefficient ( $Q$ [the capital coefficient]) and reducing the other ( $l$ [the labor coefficient])" (Laibman 1996: 47).

There is a good argument to the effect that at a given time, available technologies form a convex set in capital coefficient, labor coefficient space with a downward-sloping frontier. But the dynamic extension of that same argument leads one to expect that technical progress over time will consist in moving this frontier downwards to the left. Newly available technologies can be both capital and labor saving. Thus if actual technological change is capital using, i.e., if rather the capital coefficient rises over time, a substantive explanation is needed. 
Of course the very concept of capital in multi-good economies is troubled, as are putative statistics of capital/output ratios. But the most obvious data to come to mind provides no support for the view that the U.S. economy hews to Laibman's "consistent path." For consider the ratios of the three following nominal measures of the capital stock to output where the latter is taken as nominal GDP: 14

$$
\begin{aligned}
& \text { NPK/Y }=\text { Net Fixed Private Nonresidential Capital / GDP } \\
& N K / Y=N \text { N }+ \text { Net Government-Owned Fixed Capital / GDP } \\
& \text { NTK/Y }=\text { NetTotal15Fixed ReproducibleTangible Wealth / GDP }
\end{aligned}
$$

Consider first the period, 1929-1995, the longest for which these statistics are currently available:

\section{Capital/Output Ratios, 1929-1995}

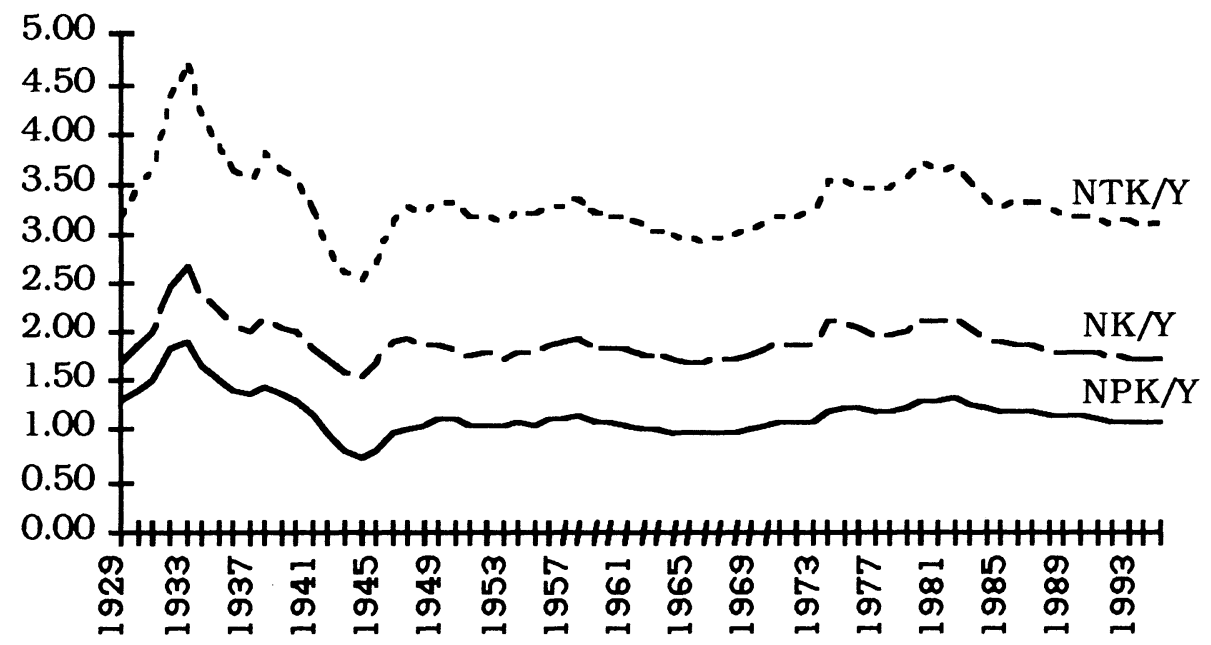

Two characteristics of this chart are evident. First, the three measures tend to move together and, second, these capital/output ratios spiked during the Great Depression and plunged during WWII, doubtless because of rapid large changes in capacity utilization. Not so evident is a long-run characteristic: over this sixty-six year period, the linear regression line slope of all three ratios is zero.

14 Capital stock data from Katz and Herman (1997), table 1. Nominal GDP data from U.S. Department of Commerce 1997, table 1.

15 I.e., NK + Net Fixed Private Residential Capital + Net Durable Goods Owned by Consumers. 
A shorter run eliminating depression and world war anomalies is the period 1950-1995:

\section{Capital/Output Ratios, 1950-1995}

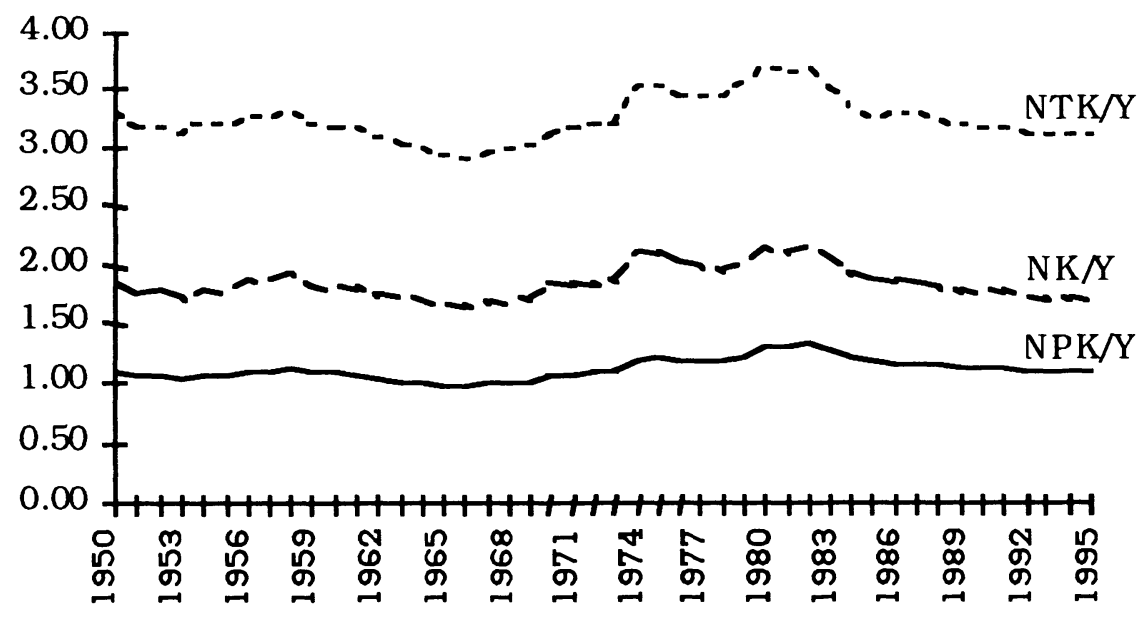

Over this forty-five year period, no trend in the three capital/output ratios strikes the eye. In fact the slopes of the linear regression lines of the three ratios are all again zero.

This data evidently provides no support for the hypothesis that aggregate technical change in the current U.S. economy is on anything resembling Laibman's "consistent path." A final chart zeroing in on capital/output ratios for the 1982-1995 period indicates that the U.S. economy has most recently been on a path quite inconsistent with Laibman's: 
Capital/Output Ratios, 1982-1995

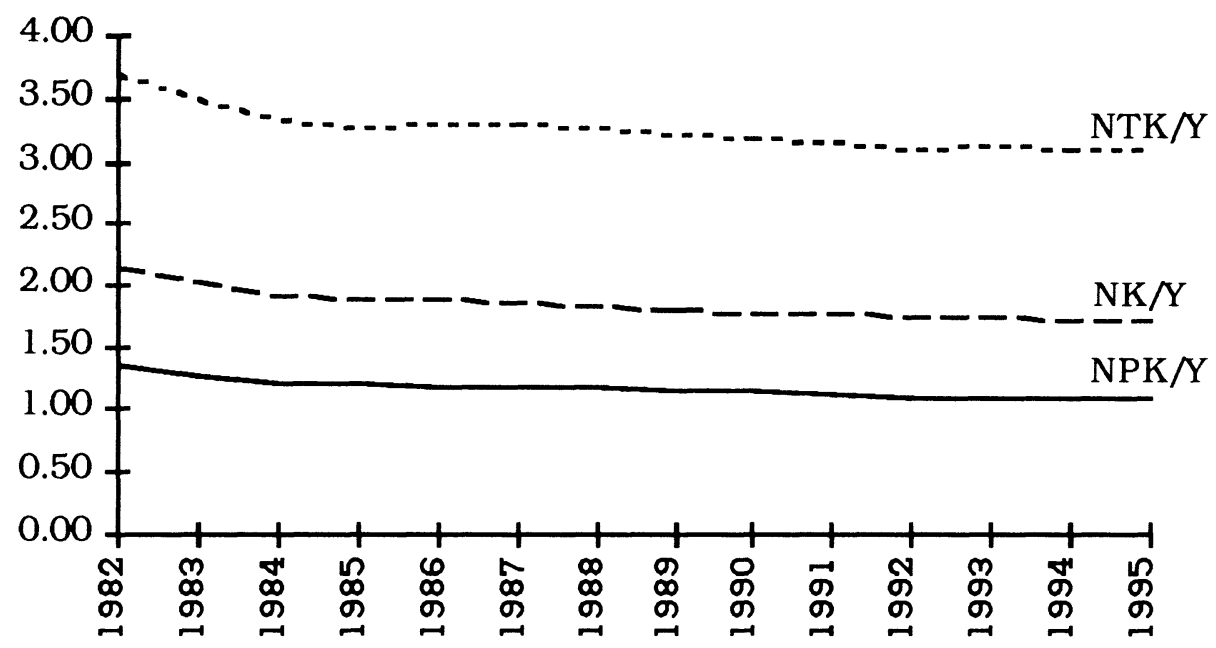

That is, since the recession of 1982 all three capital/output ratios have been steadily declining. The linear regression line slopes are all negative with average annual percentage changes of: $\mathrm{NPK} / \mathrm{Y}=-0.02, \mathrm{NK} / \mathrm{Y}=-0.03$, and $\mathrm{NTK} / \mathrm{Y}=-0.04$. Thus, given that the labor/output ratio has been decreasing steadily over the same period, the evidence strongly suggests that technical change in the United States in the recent past has been both labor saving and capital saving. Laibman's "consistent path" does not appear to be in the world we actually inhabit.16

\section{VII.}

Since the founding generation, many if not all Marxist economists have been in the grip of a certain picture: to wit that in the course of capitalist accumulation, proportionally more and more "dead" labor is worked up by less and less "living" labor, where only the latter produces surplus value and thus profit. Put unmetaphorically, in the process of capitalist development, the organic composition of capital rises (except as restrained or, even perhaps for a time, reversed by countervailing tendencies), and this rise in the organic composition of capital drives down the rate of profit.

16 Indeed, the rough constancy over time of capital/output ratios is often taken as a stylized fact of growth theory, e.g., Romer 1997: 8, 24-25. Maddison 1995: 36, on the other hand, offers striking data depicting long-term rising capital/output ratios in the most developed economies. 
Insofar as this historically enormously influential vision is actually focused on the organic composition of capital, and not instead (even if not so conceived) on accumulation, it is simply a delusion. Accumulation can of course drive down the rate of profit by the utterly straightforward mechanism of increasing the demand for labor and thus the real wage rate. But once accumulation has been taken into account, a rising composition of capital has the opposite effect. It decreases the demand for labor, and thus provides no upward pressure on the real wage rate. A rising composition of capital does not contribute to, but rather countervails, any tendency for the rate of profit to fall.

In the historically captivating picture, accumulation and a rising composition of capital are, as it were, blurred together. But in fact they are of course quite distinct. On the one hand, accumulation is increasing (non-labor) capital, a rise in $\mathrm{K}$, that is $\mathrm{K}>0$. On the other hand, a rising composition of capital is an increasing ratio of the value of (non-labor) capital (the flow of "constant capital") to the value of labor-power (the flow of "variable capital"). With value in the numerator and denominator canceling out, a rising composition of capital is a rise in $K / w L$, that is, $\gamma=(1+K) /(1+\omega)(1+\Lambda)-1>0$. Blurring together accumulation and the composition of capital depends on ignoring the fact that the denominator of the composition of capital is a function of the numerator. But when this dependence is taken into account, it becomes evident that accumulation and the composition of capital are not even positively related.

For recall first that the labor input is a function of the capital input and the technology, $L=K l / k$, which, when substituted into $K / w L$, leaves the composition of capital as $k / w l$ or, where $t=k / l$ is the technical composition of capital, simply $t / w$. That is, for a given technology or, for that matter, any other technology with the same technical composition of capital, and a given real wage rate, accumulation has no affect on the organic composition of capital. An increase in the numerator (accumulation) is canceled out by an increase in the denominator (increasing labor).

To the same point, in terms of proportional changes, the change in the labor input is $\Lambda=(1+K)(1+\lambda) /(1+k)-1=(1+K) /$ $(1+\tau)-1$, which when substituted into the expression for the change in the composition of capital leaves $\gamma=(1+\kappa) /(1+\omega)(1+\lambda)$ $-1=(1+\tau) /(1+\omega)-1$. The change in the capital input has canceled out. Whether one looks at levels or proportional changes it is clear, contrary to the traditional picture, that if the organic composition of capital increases it is due not to positive accumulation, but rather to a rise in the technical composition of capital. 
And this conclusion remains when it is taken into account that labor demand may affect the real wage rate, with the additional insight that, if anything, the effect of positive accumulation on the organic composition is negative. That is, with $\omega=\varepsilon \Lambda$ (and the Minimal Assumption that $\varepsilon \geq 0$ ), proportional change in the organic composition of capital is

$$
\gamma=\frac{1+\kappa}{\left[1+\varepsilon\left(\frac{(1+\mathrm{K})(1+\lambda)}{1+\kappa}-1\right)\right](1+\lambda)}-1=\frac{1+\tau}{1+\varepsilon\left(\frac{1+\mathrm{K}}{1+\tau}-1\right)}-1
$$

which is visibly increasing in $\tau$ and non-increasing in $\mathrm{K}$. For a given technical change, an increase in accumulation lowers, if anything, the composition of capital. I.e., if $\varepsilon>0$, an increase in accumulation lowers the composition of capital, although if $\varepsilon=0$, an increase in accumulation leaves the composition of capital unchanged.

The point of all this doubtless tedious algebra is to make conceptually palpable how accumulation and the composition of capital are related and, more to the point, how they are distinguished. In particular the point is to make clear, in contrast to the traditional received picture, that accumulation and the composition of capital are inversely related.

The prerequisite for freeing Marxist economics from the picture's grip is the Okishio Theorem. Once it is understood that if profit minded capitalists choose only viable technologies (i.e., technologies which would increase profits at current prices, then the profit rate does not fall unless the real wage rate rises), attention must be directed to how technical change and accumulation jointly affect labor demand, and thus (with, to be sure, other factors potentially no less important) the real wage rate. In the light of such attention it becomes obvious that the old picture depicted the composition of capital, as it were, upsidedown.

The Okishio Theorem is an exquisite example of that very rare species of non-trivial theorems. It shows (to be sure, only in the models in which it holds) that technical choice is not a prisoners' dilemma for capitalists. Ceteris paribus viable technical choice increases the rate of profit. On the other hand and very importantly, accumulation can be a prisoners' dilemma for capitalists. Ceteris paribus accumulation raises labor demand and, if it thereby raises the real wage rate, lowers the rate of profit. 


\section{REFERENCES}

Foley, Duncan K. 1986. Understanding Capital: Marx's Economic Theory. Cambridge: Harvard University Press.

Katz, Arnold J., and Shelby W. Herman. 1997. Improved Estimates of Fixed Reproducible Wealth, 1929-95. Survey of Current Business (May): 69-92.

Laibman, David. 1996. Technical Change, Accumulation and the Rate of Profit Revisited. Review of Radical Political Economics 28(2): 33-53.

Maddison, Angus. 1995. Monitoring the World Economy: 18201992. Paris: OECD.

Marx, Karl. 1981 (1894). Capital: A Critique of Political Economy, Volume 3. London: Pelican Books.

Romer, David. 1996. Advanced Macroeconomics. New York: McGraw-Hill.

Thompson, Frank. 1995. Technical Change, Accumulation and the Rate of Profit. Review of Radical Political Economics 27(1): 97126.

U.S. Department of Commerce, Bureau of Economic Analysis. 1997. Survey of Current Business (May): 10-29.

Frank Thompson

Department of Economics

University of Michigan

Ann Arbor, MI 48109

fthom@umich.edu 